\title{
Natural disasters, corpses and the risk of infectious diseases
}

\author{
JM Conly MD ${ }^{1}, \mathrm{BL}$ Johnston $\mathrm{MD}^{2}$
}

$\mathrm{T}$ he recent occurrence of the category 4 Hurricane Katrina devastated the United States' Gulf Coast. The hurricane caused widespread destruction and flooding, and left hundreds of thousands of people homeless. The mounting death toll was reported at almost 300 deaths as of September 8, $2005(1,2)$. The unfolding events and high death toll have left an unusual situation in which there are many decomposing corpses either lying on the streets or floating in the flood waters. The presence of these corpses in open settings, such as in public places and in the water that has inundated much of the city of New Orleans, naturally raises concerns about the occurrence of infectious disease epidemics (3). In the aftermath of large natural disasters, instinctive uncertainties arise among workers and the general population with respect to the appropriate handling and disposal of dead bodies and human remains. Given the recent occurrence of Hurricane Katrina as a large natural disaster and the unprecedented setting of the numerous corpses requiring disposal, it was considered timely to review the infectious disease risks associated with the handling of dead bodies.

The risk categorization may be examined from the perspective of the classical host-pathogen paradigm, which involves having a pathogen capable of causing invasive infection, a route of transmission and a susceptible host. Although the human body is a natural home to hundreds of species of microorganisms, the organisms involved in putrefaction (mostly anaerobic flora) are not usually considered pathogenic without a large inoculum and exposure occurrence. There are many pathogens that may be associated with human cadavers and these pathogens reflect the organisms that may be transmitted from living humans (4). With the death of a host comes the loss of the living environment for these microorganisms; ultimately, without a host, these organisms cannot sustain their growth. The time after which these once-pathogenic organisms would no longer be considered transmissible, due to their diminution or ultimate demise, depends on the host and other factors, and may be measured in hours or days (4). Organisms traditionally associated with transmission from cadavers include bloodborne viruses (HIV, hepatitis B, hepatitis C, human T-lymphotropic virus 1), enteric bacteria (Salmonella,
Shigella, Campylobacter, Yersinia, Vibrio cholerae, Vibrio vulnificus, Escherichia coli, Leptospira), viruses (rotavirus, norovirus, hepatitis A virus and enteric adenovirus), parasites (Giardia, Cryptosporidium) and airborne agents (Mycobacterium tuberculosis) (5). Although there is a risk of carriage among disaster victims, this risk is no greater than the risk of carriage in the general population. Most of the deaths in a natural disaster are due to trauma, drowning or fire, and there is no opportunity for any amplification of the pathogens that the victims may have been harbouring. Severe diseases, such as cholera or typhoid, do not typically break out after hurricanes and floods in areas where such diseases do not naturally occur (5).

A risk of gastroenteritis may be present for the general public if corpses have contaminated the water supply (6). This risk usually occurs in the later phases of a natural disaster. A study (7) in the municipal area of Villanueva, Nicaragua, which was hit by Hurricane Mitch, was conducted in a three-month period following the disaster. The study found that the incidence of acute diarrhea and acute respiratory disease significantly increased following the disaster compared with predisaster data. The incidence of acute diarrhea increased from 2849 to 6798 per 100,000 inhabitants after the disaster $(\mathrm{P}<0.01)$, while the incidence of acute respiratory disease increased from 295 to 1205 per 100,000 inhabitants $(\mathrm{P}<0.01)$. In addition, three cases of leptospirosis were ascertained, but no predisaster data were available for comparison (7). A cluster of hepatitis A infections occurred in Aceh Province, Indonesia, in the month following the tsunami that struck on December 26, 2004, but it was thought that the water-borne nature of hepatitis $A$ and other water-borne diseases that occurred were caused by a lack of safe water and sanitation and spread by overcrowding rather than through the presence of corpses $(8,9)$.

Emergency and disaster relief workers who directly handle corpses are most at risk for transmission of pathogens during these natural disasters. The occupational risks of the transmission of microorganisms to funeral home workers and pathology personnel are well known, and similar risks would be expected to exist for emergency and disaster relief workers. Most of the risks for bloodborne pathogens occur as the result of percutaneous injury or mucous membrane splashes. The risks and preventive

\footnotetext{
${ }^{1}$ Departments of Pathology and Laboratory Medicine, Medicine, and Microbiology and Infectious Diseases, Centre for Antimicrobial Resistance,

University of Calgary, Calgary, Alberta; ${ }^{2}$ Queen Elizabeth II Health Sciences Centre and Dalhousie University, Halifax, Nova Scotia

Correspondence: Dr JM Conly, Foothills Medical Centre, 1403-29 Street South, Calgary, Alberta T2N 2 T9.

Telephone 403-944-8222, fax 403-944-1095, e-mail jconly@ucalgary.ca

Received and accepted for publication September 9, 2005
} 
strategies in these settings have been well documented (10). It is important to recall that HIV may remain viable in the human body after death for up to 16 days if the body has been stored at low temperatures $\left(2^{\circ} \mathrm{C}\right)(11)$. Corpses commonly leak fecal matter, and persons handling the corpses can be exposed to organisms that may naturally exist in the gastrointestinal tract. This contact may occur through direct means with the body or indirectly through contact with the immediate contaminated environment, such as clothing, stretchers or leaking body bags. Tubercle bacilli may remain viable for extended periods of time in cadavers (12), and opportunities for aerosolization may occur when handling bodies (13). The usual exposures occur from the purging of retained fluids and/or the expulsion of air from the respiratory tract due to the putrefaction process and fluid/air buildup, particularly when the body is moved. The risk of aerosolization of any pathogenic respiratory tract organisms may be reduced by masking or placing a cloth over the mouth of the corpse.

\section{REFERENCES}

1. CBC News. Katrina death toll could be lower than feared. $<$ www.cbc.ca/story/world/national/2005/09/08/katrina_deaths overview20050908.html > (Version current at September 21, 2005).

2. US Department of State. More than 11,500 Rescued in Wake of Hurricane Katrina. <http://usinfo.state.gov/gi/Archive/2005/Sep/ 03-869118.html > (Version current at September 21, 2005).

3. de Ville de Goyet C. Stop propagating disaster myths. Lancet 2000;356:762-4.

4. Healing TD, Hoffman PN, Young SE. The infection hazards of human cadavers. Commun Dis Rep CDR Rev 1995;5:R61-8. (Erratum in 1995;5:R92).

5. Centers for Disease Control and Prevention. After a Hurricane: Infectious Disease. <www.bt.cdc.gov/disasters/hurricanes/ infectiousdisease.asp > (Version current at September 21, 2005).

6. Morgan $\mathrm{O}$. Infectious disease risks from dead bodies following natural disasters. Rev Panam Salud Publica 2004;15:307-12.

7. Campanella N. Infectious diseases and natural disasters: The effects of Hurricane Mitch over Villanueva municipal area, Nicaragua. Public Health Rev 1999;27:311-9.
Simple precautions may greatly reduce the potential risk of transmission of any pathogenic microorganisms associated with the handling of corpses. The practice of basic hygienic measures, such as handwashing, the use of universal precautions as outlined in several documents and the use of personal protective equipment will greatly mitigate the risk of transmission of any potential pathogens from corpses (10). These practices include the use of gloves when handling corpses, avoidance of handling of personal items with contaminated gloves or hands, and the use of personal protective equipment (gowns, masks and eyewear) as appropriate if splashes are anticipated.

In summary, there is no compelling evidence to suggest that corpses themselves pose a risk for an acute epidemic of an infectious disease. It is more likely that the increased risk of infection occurs in the postevent period and that a higher risk of water-borne diseases is associated with flooding where there is contamination of drinking water facilities and a lack of proper sanitation.

8. World Health Organization. Epidemic-prone disease surveillance and response after the tsunami in Aceh Province, Indonesia. Wkly Epidemiol Rec 2005;80:160-4.

9. World Health Organization. Weekly Epidemiological Record. <http://www.who.int/wer/2005/wer8018/en/index.html> (Version current at September 21, 2005).

10. Public Health Agency of Canada. Preventing the transmission of bloodborne pathogens in health care and public service settings. Canada Communicable Disease Report 1997;23S3:1-43.

11. Demiryurek D, Bayramoglu A, Ustacelebi S. Infective agents in fixed human cadavers: A brief review and suggested guidelines. Anat Rec 2002;269:194-7.

12. Centers for Disease Control and Prevention. Guidelines for preventing the transmission of Mycobacterium tuberculosis in health-care facilities, 1994. MMWR Recomm Rep 1994;43(RR-13):1-132.

13. Gershon RR, Vlahov D, Escamilla-Cejudo JA, et al. Tuberculosis risk in funeral home employees. J Occup Environ Med 1998;40:497-503. 


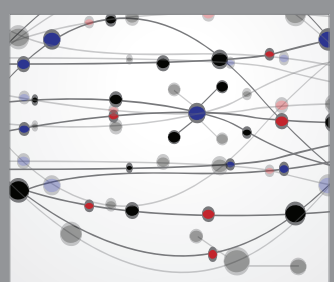

The Scientific World Journal
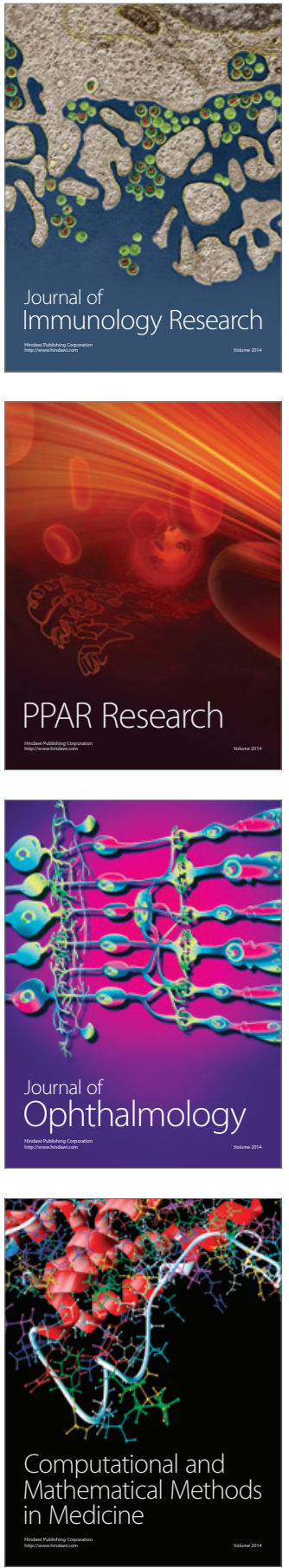

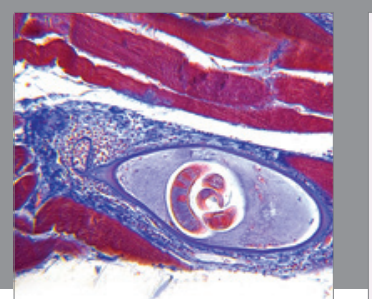

Gastroenterology Research and Practice

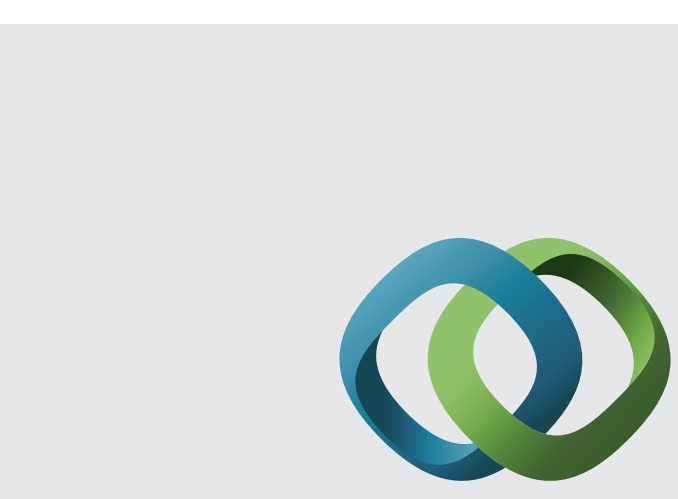

\section{Hindawi}

Submit your manuscripts at

http://www.hindawi.com
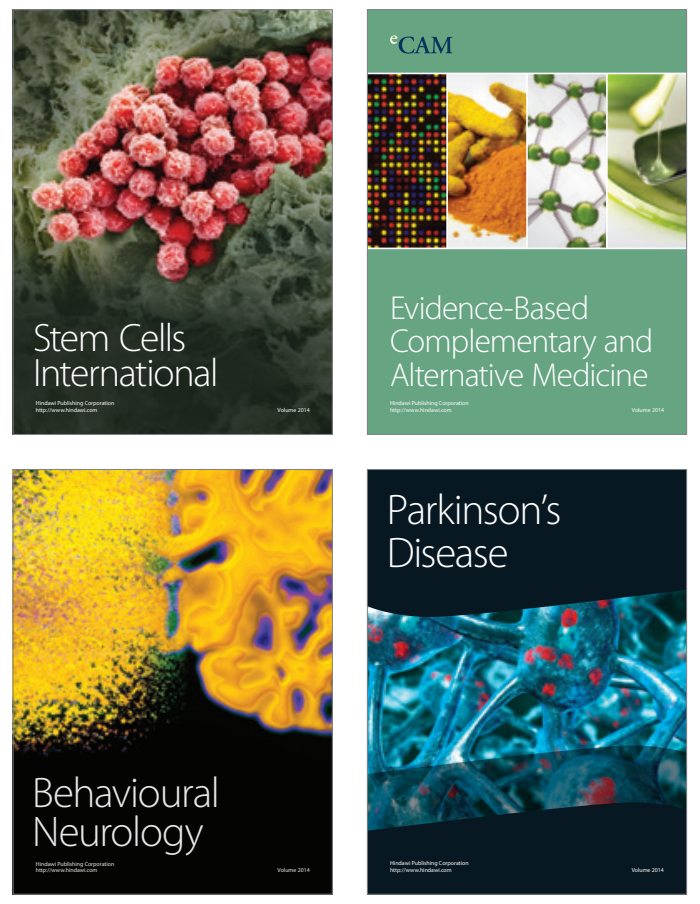
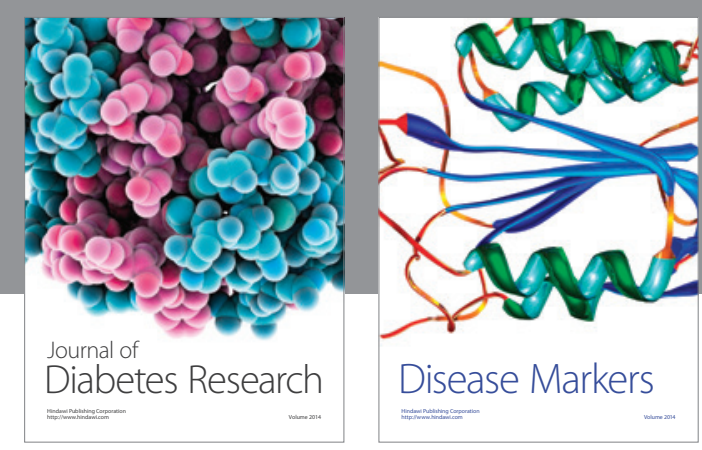

Disease Markers
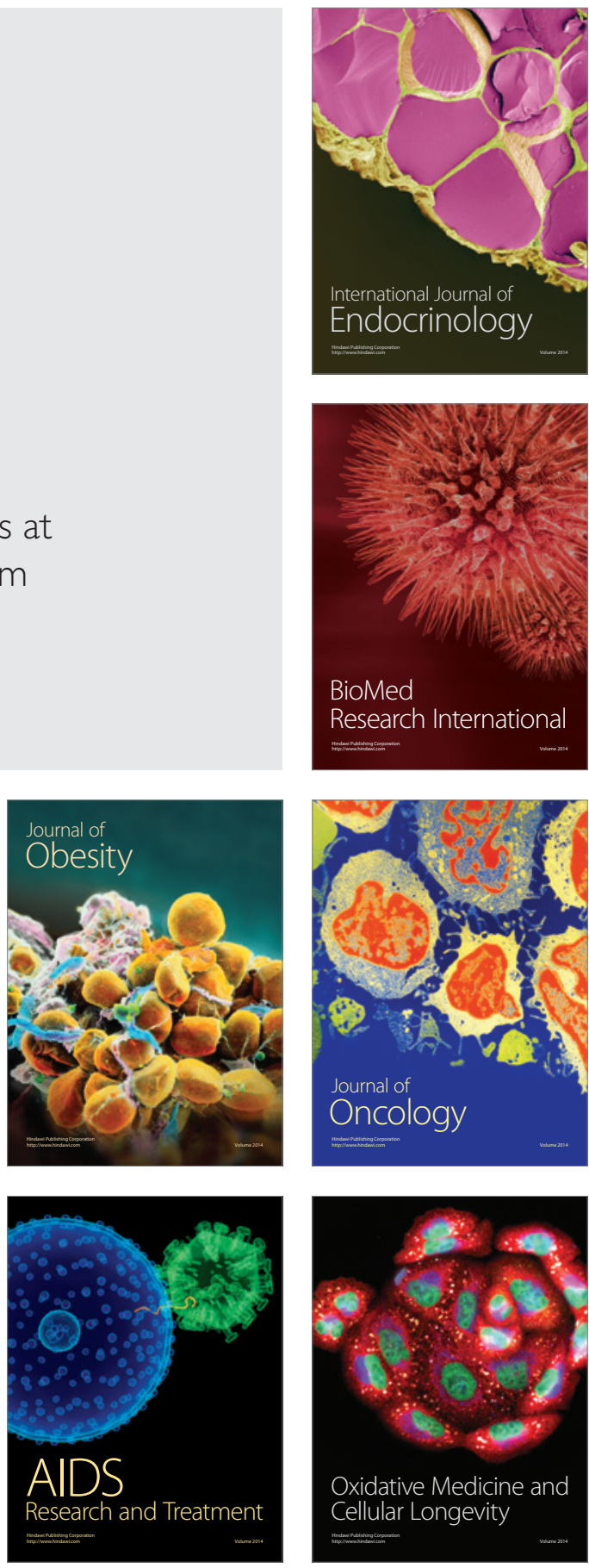